\title{
Transmissão Vertical do HIV em Fortaleza: Revelando a Situação Epidemiológica em uma Capital do Nordeste
}

Human Immunodeficiency Virus Transmission from Mother to Infant in Fortaleza: Revealing the Epidemiological Situation in a Capital of the Brazilian Northeast

Maria do Socorro Cavalcante, Alberto Novaes Ramos Junior, Terezinha do Menino Jesus e Silva, Ligia Regina Sansigolo Kerr Pontes

\section{RESUMO}

Objetivo: analisar as condutas que visam a redução da transmissão vertical do HIV nas grávidas infectadas atendidas nas maternidades públicas de Fortaleza.

Métodos: estudo descritivo no qual os bancos de dados do SINASC, SINAN e LACEN foram cruzados, procurando-se identificar as grávidas infectadas pelo HIV, seguido de busca ativa das informações complementares em prontuários médicos nas maternidades públicas.

Resultados: foram identificadas 138 grávidas infectadas pelo HIV. Observou-se que 35,5\% destas já conheciam o status sorológico antes da gravidez e 48,6\% foram diagnosticadas durante a gravidez. Das 101 grávidas que se souberam infectadas antes ou durante a gravidez, apenas 47,5\% utilizaram, de forma correta, todas as etapas da profilaxia, incluindo as condutas para o recém-nascido. Associação estatisticamente significante foi encontrada entre o conhecimento prévio da sorologia para o HIV e realização de todas as etapas adequadas de profilaxia ( $p<0,001)$.

Conclusões: encontrou-se elevado número de mulheres que não tiveram acesso às diferentes estratégias para redução da transmissão vertical, especialmente entre aquelas que engravidaram sem conhecimento de seu status sorológico. Faz-se necessária a contínua sensibilização e capacitação de todos os profissionais de saúde envolvidos com a assistência às mulheres, em geral, e às grávidas em especial, tendo em vista a aplicação correta das condutas para a redução da transmissão vertical do HIV.

PALAVRAS-CHAVE: Transmissão vertical. AIDS. Infecções na gravidez. Pré-natal.

\section{Introdução}

Nos últimos 20 anos, a epidemia da síndrome da imunodeficiência adquirida (AIDS) passou por

Universidade Federal do Ceará - Faculdade de Medicina/ Departamento de Saúde Comunitária

Correspondência:

Maria do Socorro Cavalcante

Rua da Paz 215, apto. 603 - Mucuripe

60165-180 - Fortaleza - CE

Telefone: (85) 263-6693/452-6989

Fax: (85) 452-6954/9973-9672

e-mail: socorroc@secrel.com.br

Esse trabalho é parte integrante da Dissertação "Gestantes infectadas pelo HIV: análise das condutas utilizadas na prevenção da transmissão vertical do Vírus da Imunodeficiência Humana (HIV) em Fortaleza, Ceará no período de 1999 a 2001". importantes mudanças em seu perfil epidemiológico tornando-se uma pandemia de grandes proporções, com 35 milhões de pessoas infectadas pelo vírus da imunodeficiência humana (HIV) e 20 milhões de mortes pela síndrome ${ }^{1}$.

O progressivo crescimento do número de casos de AIDS entre mulheres de todas as regiões brasileiras, em sua grande maioria por meio de transmissão sexual, vem recebendo atenção especial com o desenvolvimento de ações de prevenção e de controle da infecção, considerando-se que o maior percentual de casos é observado em mulheres em idade reprodutiva ${ }^{2,3}$.

Como conseqüência desse contexto epidemiológico e do controle da transmissão por meio de transfusões de sangue no Brasil, ao longo dos anos, a transmissão vertical, de mãe para filho, 
vem assumindo grande importância epidemiológica. Atualmente os dados epidemiológicos mostram que aproximadamente $85,0 \%$ dos casos de AIDS em menores de treze anos no Brasil têm como modalidade de transmissão do HIV, a verti$\mathrm{cal}^{2}$. Essa modalidade vem se tornando grande desafio para a saúde pública ${ }^{1}$, demandando novas estratégias de vigilância, como a vigilância da infecção pelo HIV de segunda geração, que incorpora, de forma integrada, dados relativos à infecção e aos comportamentos da população $0^{4,5}$.

No Ceará, os casos de AIDS pediátricos apresentam o mesmo perfil epidemiológico daquele observado no Brasil. Em estudo sentinela para determinar a prevalência da infecção pelo HIV em parturientes nas maternidades de Fortaleza no período de 1997, a proporção de infecção variou de 0,6 a 0,8\%, segundo dados enviados pelo Programa Nacional à Secretaria da Saúde do Estado do Ceará, ainda não publicados.

A partir da divulgação dos primeiros resultados da pesquisa desenvolvida pelo AIDS Clinical Trial Group (ACTG) 076 em 1994, tem-se disponivel importante estratégia para a redução dessa modali-

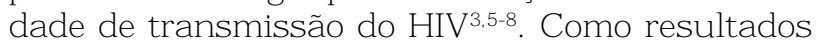
desse estudo, aconselhamento e teste anti-HIV no pré-natal e profilaxia com zidovudina (AZT) nas grávidas infectadas tornaram-se estratégias-padrão ${ }^{6}$. No Brasil, a partir de 1996, a Coordenação Nacional de DST e AIDS (atualmente, Programa Nacional de DST e AIDS) estabeleceu como meta o controle da transmissão vertical do HIV e iniciou a divulgação das ações para a sua prevenção ${ }^{2,3}$. Desde então, várias iniciativas vêm sendo estabelecidas no Brasil visando a assistência integral à grávida infectada pelo $\mathrm{HIV}^{9}$. Posteriormente, outras estratégias com esquemas abreviados de AZT e baseados em outros anti-retrovirais foram estudadas, com o objetivo de tornar mais acessiveis e efetivas as recomendações para prevenção da transmissão vertical do HIV ${ }^{10-12}$. Em meta-análise de estudos de coorte realizada em 1999, demonstrou-se que mulheres submetidas a cesarianas antes do início do trabalho de parto ou da ruptura das membranas têm risco significativamente menor de transmitir o HIV1 a suas crianças ${ }^{13}$.

Apesar dos esforços direcionados para o desenvolvimento dessas ações, os dados referentes ao monitoramento das etapas de intervenção para a prevenção da transmissão vertical do HIV ainda são escassos. Para que tais ações sejam aplicadas de maneira clara e efetiva, faz-se necessária a estruturação das ações de vigilância epidemiológica.

Assim, a vigilância dos casos de grávidas infectadas pelo HIV e crianças expostas tornou-se compulsória no Brasil em 2000, tendo, além da perspectiva epidemiológica, importante caráter operacional para a avaliação das intervenções. Serviços de saúde passaram a notificar e investigar todas as mulheres grávidas infectadas, se sua evidência laboratorial estava em conformidade com as normas e os procedimentos estabelecidos pelo Ministério da Saúde, bem como todas as crianças de mães soropositivas ou que tinham sido amamentadas por mulheres infectadas pelo HIV.

Em Fortaleza, algumas maternidades iniciaram essas ações a partir de 1998 existindo, entretanto, inúmeras falhas em relação às informações referentes ao número de mulheres grávidas infectadas, ao número de testes anti-HIV realizados, ao uso de AZT no pré-natal e parto, ao tipo de parto ao qual as parturientes foram submetidas e ao status sorológico da criança.

Em face das questões relacionadas à vigilância da transmissão vertical do HIV, esse trabalho tem como objetivo analisar as condutas profiláticas utilizadas para a redução da transmissão vertical do HIV nas grávidas infectadas que tiveram filhos nas maternidades públicas no município de Fortaleza (CE) no período de 1999 a 2001, visando fornecer informações para a efetiva implementação dessas ações de controle.

\section{Métodos}

Trata-se de estudo descritivo, de caráter retrospectivo e operacional, executado no período de março de 2002 até o final de janeiro de 2003, no Município de Fortaleza, Estado do Ceará. Os critérios de inclusão nesse estudo foram: todas as mulheres infectadas pelo HIV por método definitivo (técnica sorológica de maior especificidade ou pesquisa de antígeno do HIV) que foram identificadas pelo Laboratório Central (LACEN-CE) e que tiveram seus filhos nas maternidades públicas do $\mathrm{Mu}$ nicípio de Fortaleza no período de 1999 a 2001.

Os dados foram obtidos em duas etapas: na primeira, resgataram-se nos bancos de dados de diferentes sistemas oficiais de informação aquelas informações que não estavam disponibilizadas de forma rotineira para a Secretaria Municipal de Saúde no período de 1999 a 2001. Desta forma, o banco de dados do LACEN foi submetido a um cruzamento com dados do Sistema Nacional de Nascidos Vivos (SINASC), constituindo-se novo banco de dados composto por mulheres infectadas pelo HIV que tiveram seus filhos em maternidades públicas de Fortaleza. Posteriormente, este banco de dados, assim gerado, foi novamente cruzado com o banco do Sistema Nacional de Agravos de 
Notificação Gestante HIV positiva (SINAN), visando captar potenciais subnotificações. Todos os casos identificados que não constavam neste sistema foram notificados adequadamente ao Serviço de Vigilância Epidemiológica municipal.

Numa segunda etapa, foram investigadas as informações de todas as mulheres identificadas na etapa anterior por meio da busca ativa em prontuários médicos nas maternidades públicas, para complementação e correção de dados.

Para definição do diagnóstico de infecção pelo HIV nas mulheres incluídas no estudo foram considerados os resultados de ELISA positivo por dois métodos distintos com confirmação pela imunofluorescência (IFI) para aquelas mulheres com diagnóstico antes ou durante a gravidez ou testes rápidos em parturientes com resultado reativo, seguidos de teste ELISA e confirmados por IFI.

As variáveis estudadas foram: momento de identificação da sorologia para o HIV (antes da gravidez, durante o pré-natal, durante o parto, após o parto), ter pré-natal ou não; administração de AZT ou não no pré-natal, aplicação de AZT ou não no parto, tipo de parto, administração do AZT xarope para o recém nascido nas primeiras $24 \mathrm{~h}$, suspensão ou não do aleitamento materno e utilização do AZT xarope para o recém-nascido durante as seis semanas seguintes ao nascimento. Tendo em vista a baixa qualidade dos registros de informações nos prontuários e a impossibilidade de recuperação destas informações, variáveis como número total de consultas no pré-natal, dosagem do AZT e duração do tratamento profilático com o AZT em mulheres grávidas não puderam ser analisados, pois ou a informação não estava registrada adequadamente ou esta não existia nos prontuários em percentual muito elevado de casos.

Realizou-se análise univariada de todas as variáveis estudadas. A seguir, por meio de análise bivariada, procurou-se a existência de associação entre a mulher saber-se ou não portadora de sorologia positiva antes da gravidez e as demais variáveis relacionadas às medidas profiláticas empregadas. Utilizou-se o teste de Fisher para avaliar a associação ou não entre as proporções, considerando-se o valor de $\alpha=0,05$ como definidor do nível de significância estatística. A digitação e a análise dos dados foram realizadas no aplicativo Epi-Info, versão 6.04d do Centers for Disease Control and Prevention (CDC) de Atlanta.

Esse trabalho fez parte do estudo sobre a "Transmissão Vertical do HIV no Estado do Ceará de 1997 a 2001", que recebeu aprovação do Comitê de Ética do Hospital São José, unidade hospitalar de referência pertencente ao quadro da Secretaria de Saúde do Estado e localizada em Fortaleza.

\section{Resultados}

Do total de 138 grávidas infectadas que foram identificadas após o cruzamento de todos os bancos de dados empregados no estudo, no período de 1999 a 2001 , observou-se que 35,5\% já sabiam do seu status sorológico antes da gestação, 48,6\% souberam durante o pré-natal, ao passo que $4,3 \%$ descobriram-se infectadas pelo HIV durante o parto e $11,6 \%$ após o parto ou pelo diagnóstico da criança. Deste total, $10(7,2 \%) \mathrm{mu}-$ lheres não freqüentaram serviços de pré-natal e em $19(13,8 \%)$ casos não havia informação sobre pré-natal.

Das 109 mulheres que tiveram atendimento de pré-natal, $101(92,7 \%)$ poderiam ter sido submetidas a todas as etapas da profilaxia para a redução da transmissão vertical porque conheceram seu status sorológico antes ou durante a gravidez. Destas 101, somente 47,5\% (48/101) receberam a profilaxia completa, da forma como é preconizada pelo protocolo ACTG 076 (Figura 1). Os serviços públicos que realizaram os atendimentos de pré-natal deixaram de executar as intervenções indicadas num percentual importante de grávidas. Somente $82,1 \%(83 / 101)$ receberam a profilaxia durante o pré-natal e apenas $76,2 \%$ fizeram uso do AZT durante o parto. Verificou-se que, em $84,1 \%$ dos casos, tanto a administração da profilaxia com AZT xarope ao recém-nascido, nas primeiras 24 horas de vida, como a suspensão do aleitamento materno foram realizadas. Quanto ao tempo de uso do AZT pelo RN, apenas $61,3 \%$ das crianças o utilizaram durante seis semanas. Dois terços $(67,3 \%)$ das grávidas foram submetidas ao parto cesariano e em $70,2 \%$ não houve ruptura de membranas com mais de 4 horas (Figura 1).

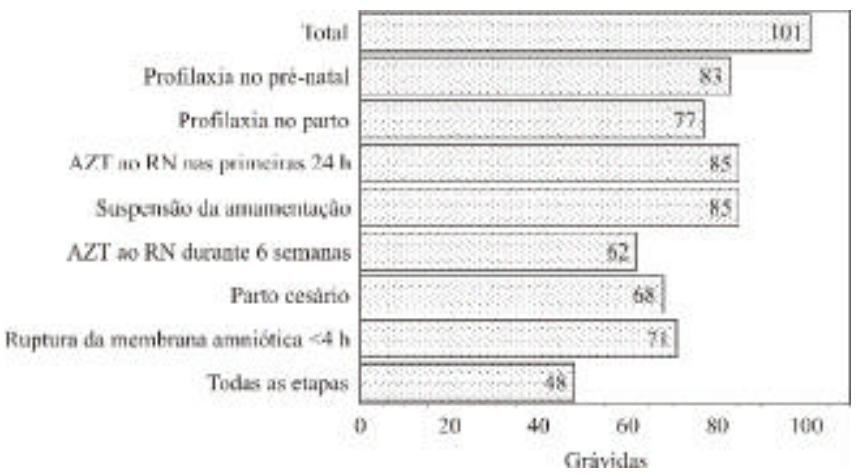

Figura 1 - Utilização das diferentes medidas profiláticas por gestantes infectadas pelo HIV que conheceram seu status sorológico antes da gravidez ou no pré-natal $(n=101)$ visando a redução da transmissão vertical, Fortaleza, 1999 a 2001. 
Com relação às 10 mulheres que não tiveram acesso ao pré-natal, apenas uma mulher teve a oportunidade de realizar algumas das etapas da profilaxia: utilização do AZT durante o parto e administração do AZT ao RN nas primeiras 24 horas de vida, bem como a suspensão do aleitamento materno. Decorre disto que nove mulheres perderam todas as chances de intervenção para a redução da transmissão vertical. Das 19 grávidas das quais não foram localizadas informações sobre pré-natal nas fichas do SINASC ou nos prontuários das maternidades, apenas seis utilizaram os três componentes do protocolo ACTG 076 (AZT no pré-natal, no parto e nas primeiras 24 horas de vida do $\mathrm{RN}$ ), 11 não receberam nenhuma intervenção e, portanto, perderam as oportunidades de prevenção, e para duas mulheres não foi possivel recuperar qualquer informação.

Mulheres que conheceram a sua soropositividade para o HIV antes da gravidez tiveram maior probabilidade de ser submetidas a todas as etapas da profilaxia para prevenção da transmissão vertical do HIV. Verificou-se associação estatisticamente significante entre o conhecimento prévio e ter recebido a profilaxia no pré-natal $(\mathrm{p}<0,001)$, ter realizado a profilaxia durante o parto $(\mathrm{p}<0,001)$, ter sido administrada a profilaxia com AZT xarope ao RN nas primeiras $24 \mathrm{~h}(\mathrm{p}<0,001)$, ter interrompido o aleitamento materno $(\mathrm{p}<0,001)$, ter sido utilizada a profilaxia com AZT xarope ao $\mathrm{RN}$ durante as seis primeiras semanas de vida $(p<0,001)$ e ter sido submetida a parto cesariano $(\mathrm{p}<0,001)$ (Tabela 1).

Tabela 1 - Número e percentual de mulheres, segundo utilização da profilaxia e conhecimento da soropositividade em Fortaleza, 1999 a 2001.

\begin{tabular}{|c|c|c|c|c|c|}
\hline \multirow[t]{2}{*}{ Variável } & \multicolumn{2}{|c|}{$\begin{array}{c}\text { Sabiam ser } \\
\text { soropositivas antes } \\
\text { da gravidez }(n=49)\end{array}$} & \multicolumn{2}{|c|}{$\begin{array}{c}\text { Não sabiam ser } \\
\text { soropositivas antes } \\
\text { da gravidez }\end{array}$} & \multirow[t]{2}{*}{$\begin{array}{l}\text { Valor de } \\
p^{*}\end{array}$} \\
\hline & $\mathrm{n}$ & $\%$ & $\mathrm{n}$ & $\%$ & \\
\hline \multicolumn{6}{|c|}{ Profilaxia pré-natal } \\
\hline Sim & 43 & 87,5 & 44 & 49,4 & \multirow[t]{2}{*}{$p<0,001$} \\
\hline Não & 5 & 10,2 & 44 & 49,4 & \\
\hline \multicolumn{6}{|l|}{ Profilaxia no parto } \\
\hline Sim & 43 & 87,5 & 42 & 47,2 & \multirow[t]{2}{*}{$p<0,001$} \\
\hline Não & 5 & 10,2 & 46 & 51,7 & \\
\hline \multicolumn{6}{|l|}{ Parto } \\
\hline Vaginal & 9 & 18,4 & 46 & 51,7 & \multirow[t]{2}{*}{$p<0,001$} \\
\hline Cesáreo & 38 & 77,6 & 40 & 44,9 & \\
\hline \multicolumn{6}{|c|}{$\begin{array}{l}\text { Profilaxia com AZT nas primeiras } 24 \\
\text { horas para o RN (xarope) }\end{array}$} \\
\hline Sim & 46 & 93,9 & 52 & 58,4 & \multirow[t]{2}{*}{$p<0,001$} \\
\hline Não & 1 & 2,0 & 34 & 38,2 & \\
\hline \multicolumn{6}{|c|}{ Aleitamento materno } \\
\hline $\operatorname{Sim}$ & 3 & 6,1 & 28 & 31,5 & \multirow[t]{2}{*}{$p<0,001$} \\
\hline Não & 44 & 89,8 & 55 & 61,8 & \\
\hline \multicolumn{6}{|c|}{ Tempo AZT xarope ao RN } \\
\hline Seis semanas & 34 & 69,4 & 37 & 41,6 & \multirow[t]{2}{*}{$p<0,001$} \\
\hline Não usou & 1 & 2,0 & 28 & 31,5 & \\
\hline
\end{tabular}

*Teste de Fisher.

**Excluídos os casos ignorados.

Até o final de janeiro de 2003, a situação das crianças expostas ao HIV tinha o seguinte perfil: 51 (37,0\%) crianças não procuraram o ambulatório de referência para o acompanhamento, $48(34,8 \%)$ encontravam-se em acompanhamen- to, mas tinham o diagnóstico indeterminado, 32 $(23,2 \%)$ não se encontravam infectadas e $7(5,1 \%)$ estavam com diagnóstico definido de infecção pelo HIV. Destas sete crianças, duas mães souberam estar infectadas durante o pré-natal, uma soube 
durante o parto e as outras quatro apenas após o parto, por meio do diagnóstico da criança, portanto, a maioria não utilizou nenhuma conduta profilática e no restante, não foram utilizadas todas de forma correta.

\section{Discussão}

Logo após as recomendações do U.S. Public Health Service (PHS) no ano de 1994, baseadas na utilização do AZT para a redução da transmissão vertical do $\mathrm{HIV}^{6,8}$, foram estabelecidas diretrizes voltadas para o aconselhamento voluntário e teste de todas as mulheres com o objetivo de conhecer o status sorológico antes de se tornarem grávidas. No caso de elas já terem engravidado, o PHS oferecia o teste e o aconselhamento como rotina do serviço para o início das intervenções.

No Brasil, desde 1997 foi recomendada a oferta universal do teste anti-HIV no pré-natal ${ }^{2,3}$. Entretanto, apesar dos avanços, ainda não há dados epidemiológicos concretos sobre o número de mulheres grávidas infectadas no Brasil, bem como sobre a forma como as ações para prevenção da transmissão vertical do HIV estão sendo operacionalizadas.

Os resultados deste estudo mostraram que a proporção de mulheres que souberam estar infectada pelo HIV antes da gravidez (pouco mais de um terço) ainda é muito pequena. O fato de a maioria destas (quase dois terços - 31/49) serem casos de AIDS e não apenas terem sorologia positiva para o HIV (dados não descritos neste trabalho) reforça a dificuldade, no contexto atual, de a mulher ter oportunidade de conhecer seu status sorológico antes de se tornar sintomática para a doença. Isto sugere a necessidade do oferecimento mais amplo do teste entre a população feminina em geral, mediante o aconselhamento ${ }^{14}$, principalmente antes de engravidar ou planejar a gravidez. Este seria o momento desencadeador de todas as ações de prevenção da transmissão vertical do HIV, quando as mulheres teriam o conhecimento dos benefícios da profilaxia tanto para o seu bebê como também para si mesma. Além disto, aumentar a percepção de risco das mulheres, por meio de processos preventivos voltados a este propósito seria, também, fundamental.

Estudo realizado em ambulatório de DST e AIDS em São Paulo mostrou que a intenção das mulheres infectadas pelo HIV de ter filhos não se alterou substancialmente ${ }^{15}$. Desta forma, é necessário que todos os serviços de atenção à saúde respeitem os direitos reprodutivos e sexuais das mulheres HIV positivas, oferecendo as condições adequadas para esta mulher grávida e seu concepto.

Observou-se, no presente trabalho, que a oferta e execução de todas as etapas que visam a redução da transmissão vertical, incluindo o RN, ficaram restritas a menos da metade de todas as mulheres grávidas que, por terem realizado prénatal ou terem conhecido seu status sorológico previamente, poderiam tê-las recebido adequadamente. Portanto, é de fundamental importância que se cumpra todo o fluxograma do diagnóstico da infecção pelo HIV nos serviços que prestam atendimento de pré-natal e parto, para que haja melhor assistência integral à grávida e à criança, aplicando-se todas as condutas profiláticas de maneira correta, evitando-se um número excessivo de perdas.

As mulheres que já conheciam seu status sorológico antes da gravidez tiveram muito mais chance de receber todas as etapas de prevenção da transmissão vertical do que aquelas que o souberam durante a gravidez. Por outro lado, as mulheres que tiveram o diagnóstico tardio, ou no momento do parto ou após o parto, perderam todas as oportunidades da realização da profilaxia. Apesar de oito destas terem sido atendidas no prénatal, nenhuma conduta profilática foi utilizada.

Este conhecimento antes da gravidez permite aos profissionais de saúde iniciar precocemente a profilaxia durante o pré-natal e parto, administrar o AZT nas primeiras vinte e quatro horas de vida da criança, contra-indicar a amamentação pela mãe e aleitamento cruzado, prescrever o AZT xarope para as crianças durante as primeiras seis semanas de vida, indicar parto cesáreo eletivo e encaminhar as mães e crianças ao serviço de referência para acompanhamento ambulatorial especializado na infecção pelo HIV e AIDS.

Observou-se, portanto, que a mulher saberse positiva antes da gravidez permite que estas mulheres tenham melhor acompanhamento e uma melhor qualidade na assistência integral ao parto e pré-natal, em razão de já serem seguidas no ambulatório de infectologia. Apesar deste melhor acompanhamento, muitas destas gravidezes podem ser indesejadas. Estudo realizado numa das regiões mais desenvolvidas do país alerta que o uso de contraceptivo, por parte de mulheres com HIV ou AIDS, pode estar sendo inadequado, gerando a gravidez indesejada ${ }^{15}$.

A grande maioria das grávidas que não tiveram acesso a consultas de pré-natal $(9 / 10)$ perdeu as chances de receber a profilaxia, tendo apenas uma delas realizado somente algumas das diferentes etapas. Da mesma forma, daquelas mulheres 
para as quais não se dispunha de informações sobre o pré-natal, na ficha de investigação, mais da metade perdeu a oportunidade de receber a profilaxia. Isto permite concluir que a perda da oportunidade de realizar o pré-natal também leva à perda na realização das etapas da profilaxia para a redução da transmissão vertical do HIV.

É importante ressaltar que boa cobertura e qualidade da assistência pré-natal influenciam significativamente o resultado das ações implementadas, favorecendo a redução do coeficiente de mortalidade materna e da freqüência de transmissão vertical, seja do HIV ou do Treponema pallidum, agentes passiveis de transmissão por essa via.

Trabalho realizado em São Paulo constatou uma cobertura de pré-natal elevada de $94,0 \%$ entre 116 mulheres que estavam infectadas pelo HIV, corroborando os dados encontrados em outros trabalhos realizados na mesma localidade, onde a freqüência de pré-natal se manteve elevada nos últimos dez anos ${ }^{16}$. Em Fortaleza, embora a cobertura de pré-natal observada neste estudo não tenha sido tão elevada, foi encontrada a mesma cobertura nas mulheres infectadas e nas mulheres em geral, segundo dados do SINASC, no ano de 2001 $(79,0 \%)$. Isto significa que todas estas mulheres, nestas condições, deveriam ter tido a oportunidade de realizar as condutas profiláticas para a prevenção da transmissão vertical do HIV.

Um indicador direto de bom atendimento pré-natal é a freqüência da mulher em, no mínimo, quatro a cinco consultas durante a gravidez, considerando pré-natal ideal aquele em que há seis ou sete consultas ${ }^{17}$, o que contribui para melhor aconselhamento, realização do teste anti-HIV e efetiva utilização da terapia anti-retroviral (AZT), aumentando as chances das crianças nascerem livres da infecção. A qualidade da informação dada à mulher durante o pré-natal e a forma como ela é recebida nos serviços são aspectos fundamentais para o adequado aconselhamento. Entre mulheres que freqüentaram o pré-natal em São Paulo e não souberam da positividade (19/116), 70,0\% reclamaram que o profissional não explicou a importância do teste, $80,0 \%$ não souberam dos riscos para a criança e para $75,0 \%$ não foi explicada a importância do tratamento ${ }^{16}$.

Segundo dados não publicados da Sala de Situação Epidemiológica de Fortaleza, tendo como fonte as informações do SINASC em 2003, das 41.311 gestantes inscritas no pré-natal em 2001, apenas nove por cento realizaram entre uma a três consultas, $43,0 \%$ realizaram quatro a seis e $39,0 \%$ realizaram sete ou mais consultas. O percentual de mulheres que não realizou nenhu- ma consulta foi de $3,0 \%$, sugerindo que a maioria teve a oportunidade de obter melhor qualidade das informações referentes ao pré-natal.

Em relação às crianças, observou-se, no presente estudo, percentual razoável $(84,1 \%)$ de utilização do AZT xarope nas primeiras 24 horas de vida e de uso do leite artificial. Isto confirma a possibilidade do tratamento da criança em tempo hábil durante o parto e melhor orientação da mãe quanto à suspensão da amamentação durante o pré-natal ou parto. No entanto, o mesmo não ocorreu em relação à continuidade de utilização do AZT xarope durante as primeiras seis semanas de vida para o recém-nascido, tempo estabelecido pelo protocolo ACTG 076.

Em trabalho realizado no Rio de Janeiro, utilizando-se abordagem com equipe multidisciplinar, foram avaliadas as ações para a prevenção da transmissão vertical do HIV. Mostrou-se que, com adequado treinamento para uma equipe multiprofissional constituída por infectologistas, obstetras, pediatras, enfermeiras, psicólogas e assistentes sociais no acompanhamento das grávidas infectadas e de seus bebês, foi possivel reduzir para $2,8 \%$ a transmissão vertical do HIV, niveis similares aos de outros países, a maioria desenvolvidos ${ }^{18}$.

A operação cesariana foi a técnica cirúrgica mais utilizada para resolução das gravidezes nas 101 mulheres $(67,3 \%)$ que conheciam seu status sorológico nesse estudo. Como já referido anteriormente, vários trabalhos demonstraram a redução das taxas de transmissão em mulheres que utilizaram o AZT e foram submetidas à cesárea eletiva. Uma meta-análise realizada em 1999 publicou taxas de $8,2 \%$ de transmissão vertical em mulheres submetidas à cesariana e sem fazer uso de AZT e de 2,0\% nas mulheres sob uso de $\mathrm{AZT}^{13}$.

Com relação ao encerramento dos casos das crianças deste estudo, o que mais chamou atenção foi a grande quantidade de crianças com perda de seguimento ou sem diagnóstico definido, por não ter nenhuma medida de carga viral ou ter apenas uma carga viral ou cargas virais ainda discordantes, ficando, assim, com diagnóstico indeterminado. Este considerável número de resultados indeterminados e com perda no seguimento das crianças acarretou enorme prejuízo na definição das taxas de transmissão do HIV nessa população. Por essa razão, estudos complementares estão sendo desenvolvidos no sentido de recuperar as informações das crianças cuja situação da infecção pelo HIV ainda estão indisponíveis, por meio de acompanhamento dessas crianças para definição do status sorológico.

Os dados obtidos a partir desse estudo tornam evidente a dificuldade de se implementar as reco- 
mendações do protocolo ACTG 076, quase dez anos após a sua publicação, e que essa situação representa uma realidade de grande parte dos serviços que abordam a questão da transmissão vertical do HIV em Fortaleza. Assim, a ampliação da oferta do teste anti-HIV para a população feminina em geral, uma boa cobertura de assistência pré-natal, assim como a melhoria na sua qualidade, são de fundamental importância para a aplicação correta das condutas profiláticas, reduzindo as perdas na oportunidade da utilização da profilaxia. Portanto, a sensibilização, a mobilização e a capacitação de todos os profissionais envolvidos na assistência à gestante e dos gestores permitirão a redução da transmissão vertical a níveis indetectáveis. Apenas por meio desse processo coletivo e multiprofissional de ação é que esse desafio, e tantos outros do dia-a-dia, como por exemplo, a abordagem de casais sorodiscordantes ${ }^{19}$ que procuram os serviços de saúde para buscar informações seguras sobre os riscos de uma gravidez, é que se poderá pensar em um processo efetivo de prevenção da transmissão vertical do HIV.

\section{ABSTRACT}

Purpose: to analyze the management for reduction of $H I V$ transmission from mother to infant in infected pregnant women who delivered in public maternity hospitals of the municipality of Fortaleza, Ceará, from 1999 to 2001.

Methods: a descriptive study where data of SINASC, SINAN and LACEN data bank systems were cross-checked looking for HIV-infected pregnant women, followed by an active search for complementary information on the subject through medical records of the maternity hospitals.

Results: a hundred and thirty-eight pregnant women infected with HIV were identified. It was observed that $35.5 \%$ knew their serum status before pregnancy and $48.6 \%$ (67/138) were diagnosed during the prenatal visits. Of those 101 women that knew their serum status before or during pregnancy, only $47.5 \%$ followed all steps of prophylaxis, including the management of the newborns. The previous knowledge of the serum status was found to be significantly related to following the correct steps of prophylaxis $(p<0.001)$.

Conclusions: an increasing number of women who had no access to the different strategies for the reduction of vertical transmission were found in Fortaleza, Ceará, especially among those who became pregnant without knowing their serum status. Continuous awareness and training are very important for all health care providers involved in attending the pregnant women for the application of correct management in order to reduce HIV transmission from mother to infant.

KEYWORDS: Vertical transmission. Human immunodeficiency virus. Infectious diseases. Prenatal care.

\section{Agradecimentos}

À Fundação Cearense de Apoio ao Desenvolvimento Científico e Tecnológico (FUNCAP) pela concessão de bolsa de Mestrado.

\section{Referências}

1. World Health Organization. Joint United Nations Program on HIV/AIDS (UNAIDS), 2001. AIDS epidemic update. Geneva: WHO; 2002.

2. Boletim Epidemiológico AIDS. Ministério da Saúde. Brasília 2002; 16(1).

3. Boletim Epidemiológico AIDS. Ministério da Saúde. Brasília 1999; 12(1).

4. UNAIDS,WHO. Guidelines for second generation HIV surveillance: the next decade. Geneva: WHO; 2000.

5. Ministério da Saúde. Coordenação Nacional de DST e AIDS. Vigilância do HIV no Brasil: novas diretrizes. Brasília: Coordenação Nacional de DST e AIDS; 2002. p.82.

6. U.S. Public Health Service recommendations for human immunodeficiency virus counseling and voluntary testing for pregnant women. MMWR Recomm Rep 1995; 44:1-15.

7. Connor EM, Sperling RS, Gelber R, et al. Reduction of maternal-infant transmission of human immunodeficiency virus type 1 with zidovudine treatment. N Engl J Med 1994; 331:1173-80.

8. Centers for Disease Control and Prevention (CDC). Recommendations of the U.S. public health service task force on the use of zidovudine to reduce perinatal transmission of human immunodeficiency virus. [S.1.]: CDC; 1994. p.1-20.

9. Lambert JS, Nogueira SA. Manual para o acompanhamento clínico da gestante infectada pelo HIV. Rio de Janeiro: Programa de Assistência Integral à Gestante HIV Positiva; 2002. p.104.

10.Shaffer N, Chuachoowong R, Mock PA, et al.. Shortcourse zidovudine for perinatal HIV-1 transmission in Bangkok, Thailand: a randomised controlled trial. Lancet 1999; 353:773-80.

11.Lallemant M, Jourdain G, Kim S, et al. Perinatal HIV Prevention Trial (PHPT), Thailand: DSMB recommends termination of short-short arm after first interim analysis. Program and abstracts of the $2^{\text {nd }}$ Conference on Global Strategies for the Prevention of HIV Transmission from Mothers to Infants; 1999 Sep 1-6; Montreal, Canada. Montreal; 1999.

12.Ministério da Saúde. Coordenação Nacional de DST e AIDS. AIDS: recomendações para prevenção da transmissão vertical do HIV - 2002/2003. Brasília: Coordenação Nacional de DST e AIDS; 2002. 
13.The International Perinatal HIV. The mode of delivery and the risk of vertical transmission of human immunodeficiency virus type 1: a metaanalysis of 15 prospective cohort studies. N Engl J Med 1999; 340:977-87.

14.Ministério da Saúde. Coordenação Nacional de DST/ AIDS. Aconselhamento em DST/HIV e AIDS: diretrizes e procedimentos básicos. Brasília: Coordenação Nacional de DST/AIDS; 1999.

15.Santos NJS, Buchalla CM, Fillipe EV, Bugamelli L, Garcia S, Paiva V. Mulheres HIV positivas, reprodução e sexualidade. Rev Saúde Pública 2002; 36 Suppl:12-23.

16. Marques HHS, Latorre MRDO, DellaNegra M, Pluciennik AMA, Salomão MLM. Falhas na identificação da infecção pelo HIV durante a gravidez em São Paulo, SP, 1998. Rev Saúde Pública 2002; 36:385-92.

17.Ministério da Saúde. Assistência pré-natal. Manual Técnico. Brasília: Ministério da Saúde; 2000.

18. Nogueira SA, Abreu T, Oliveira R, et al. Successful prevention of HIV transmission from mother to infant in Brazil using a multidisciplinary team approach. Braz J Infect Dis 2001; 5:78-86.

19.Maksud I, Terto Júnior V, Pimenta MC, Parker R, organizadores. Conjugalidade e AIDS: a questão da sorodiscordância e os serviços de saúde. Rio de Janeiro: Associação Brasileira Interdisciplinar de AIDS; 2002.

Recebido em: 18/12/2003

Aceito com modificações em: 6/2/2004 